the common garter snake of North America can mate either in the autumn or in the spring. F. C. Blanchard has investigated the matter more fully and found ovidence to show that effective mating occurs commonly in the autumn in the wild state. The offspring from such matings, if the females are kept isolated, exhibit normal Mendelian ratios in their colour pattern. In the wild, such females may copulate again in the spring and the resulting offspring show colour patterns that bear no relationship to any Mendelian ratio, and so it would appear that the actual insemination resulting from the autumn mating does not occur until after the spring mating. W. C. Beckman shows that in a number of game fishes in Michigan, temperature plays the leading part in the annulus formation in the scales. The mean temperature of the first days on which the majority of the scales showed an annulus is $58^{\circ} \mathrm{F}$. An interesting paper by C. L. Hubbs and R. R. Miller deals with the influence of changed environment upon interspecific hybridization of two generations of Cyprinodont fishes.

\section{Quality Control Technique}

A USEFú booklet entitled "Quality Control Chart Technique when Manufacturing to a Specification", by B. P. Dudding and W. J. Jennett, has recently been published by the General Electric Co., Ltd., of England (Research Laboratories, G.E.C., Wembley. 2s. 6d.). The booklet describes a more detailed development of the principles discussed in British Standard $600 R$ (1942), and the major aim of the technique described is to assist production to specification requirements with the elimination of waste labour and material. While the handbook is intended principally as a guide for those concerned with the machine manufacture of articles to dimensional limits, it should be helpful to anyone introducing the technique for use in other types of manufacture. The book is arranged in two parts with appendixes. Part 1 deals with quantitative data and is concerned with the utilization of results of measurement. Part 2, giving qualitative data, is concerned with the utilization of the results of classifying a product into categories as, for example, 'defective' and 'effective'. Suggestions are made with the view of increasing the value of control charts for number defective in those cases where this method has to be adopted or it is preferred on grounds of convenience and/or cost.

\section{Production Control in Industry}

UNDER the title "Production Control in the Small Factory : Office Aid to the Factory" (B.S. 1100. Part 2. 1944), the British Standards Institution has issued a booklet designed to advise on production control technique in the small factory. The need is stressed for control in order to make it possible economically to increase production and to eliminate waste of time and effort. The practice and procedure recommended are illustrated by taking as example a firm in which between fifty and sixty people are employed in the manufacture of jigs and fixtures for small assemblies. The number of schedules, records and documents is kept down to the minimum for simple control over issuing quotations, purchasing and stock, volume of work to be handled, flow of work to shops, production instructions, time-keeping and costs. The methods described are illustrated with specimen schedules, cards, record sheets, and a comprehensive order flow chart, which shows the various stages through which an order will pass. By careful study of these recom. mendations, factory managers should be able to adapt them to their firm's individual needs.

\section{Lighting Reconstruction}

THE Illuminating Engineering Society has now issued the fifth of the series of its Lighting Reconstruction Pamphlets, the present one dealing with city and highway public lighting. The pamphlet discusses what might well be done in the way of public lighting in the post-war period, and it offers useful guidance, with the view of achieving maximum benefit to those concerned. The pamphlets are obtainable from the Society at 32 Victoria Street, London, S.W.1, at the uniform price of $1 s$. each, 9s. a dozen or $£ 3$ a 100 .

\section{Announcements}

Mr. George SMith, of the London School of Hygiene and Tropical Medicine, has been elected president of the British Mycological Society for 1945.

AT the meeting of the London Mathematical Society on January 25 , at 3.0 p.m., in the rooms of the Royal Astronomical Society in Burlington House, Prof. J. Hadamard, of the Paris Academy of Sciences, will give his postponed lecture "Psychological and Personal Recollections of a Mathematician". Members of other scientific societies will be welcome.

A COMPREHENSIVE review of progress in industrial and medical radiology is contributed by Bernard John Leggett to the November issue of the Journal of the Institution of Electrical Engineers (91, Part 1, No. 47). The paper reviews atomic physics, the cyclotron and betatron, the generation of high voltage and design of high-voltage $\mathrm{X}$-ray tubes, industrial radiology, medical radiology and bio-electric phenomena. A bibliography of sixty-seven items accompanies the paper.

AN Annotated Bibliography of Medical Mycology, edited by Dr. S. P. Wiltshire, in collaboration with Dr. Charles Wilcocks and J. T. Duncan (Imperial Mycological Institute, Kew, Surrey, 1944. Pp. 32. $5 s$.), lists all papers on medical mycology which were either published in 1943 or noted by abstracting journals during that year. Authors and subjects are indexed. Short summaries follow most of the heardings. If these summaries can be enlarged in future years, the value of this publication will be greatly enhanced. The Bibliography can be recommended as a work of reference for dermatologists and pathologists.

Catalogue 63 of scientific books issued by Ifan Kyrle Fletcher, "Merridale", Caerleon, Mon., contains among others the following works of interest : Andrea Bacci's "De thermis libri system" (1571), Bateman's "Practical Synopsis on Cutaneous Diseases" (1824), first edition of Sir Thomas Browne's work (1686), Cheselden's "Anatomy of the Human Body" (1741), Cornaro's "Discourse on a Sober and Temperate Life" (1779), Fabricius ab Aquapendente's "Opera omnia anatomica et physiologica" (1687), John Freind's "Opera omnia" (1723), Sir John Harington's "Metamorphosis of Ajax" (1814), J. F. C. Hecker's "Epidemics of the Middle Ages" (1846), "Lunacy Acts" (1798-1824) and Mesué's "De re medica" (1542). 